\title{
Clotting and fibrinolysis
}

\author{
C. R. M. PRENTICE \\ From the University Department of Medicine, Royal Infirmary, Glasgow
}

Vascular disease accounts for more than $50 \%$ of deaths and in most cases the cause lies in obstruction to blood flow by the twin perils of atheroma formation and thrombosis.

The major constituents of thrombi are platelets and fibrin, together with trapped red cells and other elements. Our main antithrombotic drugs are the antiplatelet agents to prevent platelets sticking together; anticoagulants to prevent fibrin formation; and fibrinolytic agents which, hopefully, will lyse and remove formed fibrin deposits. Antithrombotic therapy may also conveniently be classified as (1) prophylactic, to cover an event, such as a surgical operation, known to be associated with an increased thrombotic risk, and (2) therapeutic, to treat a thrombus which has already formed. It must also be remembered that the problems of arterial and venous thrombosis are different. Arterial thrombi are composed largely of aggregated platelets, together with fibrin; it is thought that platelet adhesion to the vessel wall is an important event which may initiate arterial thrombosis. Conversely, thrombi formed in veins consist mainly of fibrin and it is in this situation where the conventional anticoagulants are likely to be useful.

\section{Antiplatelet Agents}

First, I will give a brief account of the platelet aggregation process, and then continue with an account of the proposed mechanism by which some of the antiplatelet agents operate. Activation of the platelet membrane can be carried out by stimuli, such as ADP, collagen, basement membrane, thrombin, adrenaline, serotonin, and antigenantibody complexes. The common pathway of activation may be related tc the level of cyclic-AMP within the platelet. Most of the aggregating agents tend to diminish cyclic-AMP production by inhibiting adenylcyclase, as seen in the figure. Conversely antiplatelet agents increase the level of platelet cyclic-AMP. This is achieved in two ways. First, increased production of cyclic-AMP by stimulation of adenylcyclase activity is caused by agents such as the prostaglandins. Second, the dipyridamole group of drugs causes decreased degradation of cyclic-

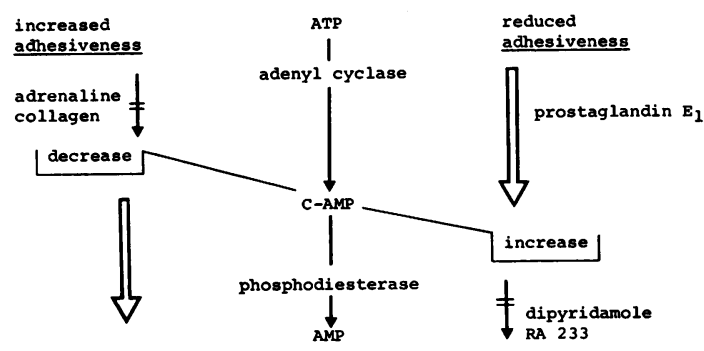

Fig Possible mechanism by which platelet metabolism may be affected by aggregating agents and inhibitory drugs

AMP by inhibition of phosphodiesterase. The different groups of platelet-inhibitory drugs are the anti-inflammatory drugs-acetylsalicylic acid, indomethacin, sulphinpyrazone-dipyramidole (RA 233), the prostaglandins, and the dextrans. The aspirin and anti-inflammatory group of drugs have probably a different inhibitory mechanism. They appear to stabilize the platelet membrane and also the lyzosomal membranes, inhibiting release of lyzosomal enzymes. This subject has been reviewed by Vermylen, de Gaetano, and Verstraete (1973).

INDICATIONS FOR ANTIPLATELET AGENTS The therapeutic trials for antiplatelet agents are still in their infancy but the probable and possible indications are shown in table I. If the antiplatelet agents were found to have a prophylactic effect against myocardial infarction this would represent a major advance. We are still dealing with the first generation of antiplatelet agents and it is probable

\begin{tabular}{ll}
\hline Indication & Condition \\
\hline Definite & Nil \\
Probable & Embolism from prosthetic heart valves \\
Possible & $\begin{array}{l}\text { Myocardial infarction-secondary prevention } \\
\text { Transient cerebral ischaemia } \\
\end{array}$ \\
& Extracorporeal bypass circulations \\
\hline
\end{tabular}

Table I Indications for antiplatelet agents 
that the development of new derivatives and combination therapy regimes will improve their effectiveness in the future.

One advantage of the antiplatelet agents is that they appear to be free from haemorrhagic complications. This is in contrast to the anticoagulants and fibrinolytic agents, both of which are associated with significant haemorrhagic side effects.

\section{The Anticoagulants}

The anticoagulants inhibit the coagulation enzyme sequence which causes fibrin formation. Anticoagulants form three main groups: heparin, the coumadin compounds, and ancrod.

\section{HEPARIN}

Heparin is an immediately acting, negatively charged mucopolysaccharide prepared from animal lung or intestinal mucosa. Heparin BP is a heterogeneous compound having molecules of widely differing molecular weights, although the main component is about $22000 \mathrm{mw}$. When administered intravenously it acts as a potent, immediately acting inhibitor of thrombin and activated factor $\mathrm{X}$ as well as possibly other coagulation factors. Heparin first combines with antithrombin III, an alpha globulin of molecular weight 64000 . A low level of antithrombin III may reflect a predisposition to thrombosis. For this reason, antithrombin III concentration is frequently measured by the immunological technique. But we have not been able to find a correlation between the biological and immunological assays of antithrombin III, reflecting, in all probability, that there are numerous antiproteases in the circulation which can inhibit thrombin (Whigham, Howie, Forbes, and Prentice, unpublished).

The two main methods of giving heparin are either by six hourly intermittent injections or by continuous intravenous infusion. We prefer the latter method as a more uniform plasma concentration is obtained, although neither method has been the subject of sufficient clinical evaluation.

One problem about heparin in the treatment of arterial thrombosis is that it may enhance platelet aggregation. We have studied the effects of therapeutic concentrations of heparin in modifying ADPinduced platelet aggregation. Heparin enhanced the aggregating effect of ADP and lowered the threshold at which the release reaction and secondary platelet aggregation took place (Thomson, Forbes, and Prentice, 1973). We have also found that platelet deposition and fibrin formation may take place on extracorporeal membranes during haemodialysis, despite the fact that the patient is heparinized sufficiently to prolong the whole blood clotting time to over 60 minutes (Lindsay, Prentice, Ferguson, Burton, and McNicol, 1972).

ORAL ANTICOAGULANTS

These drugs act as vitamin $\mathrm{K}$ antagonists, blocking the action of vitamin $K$ in completion of the synthesis of factors II (prothrombin), VII, IX, and $\mathrm{X}$. The drugs most widely used in Britain are warfarin sodium and phenindione. In the absence of vitamin $\mathrm{K}$, either due to deficiency or the presence of the oral anticoagulants, precursor molecules of factors II, VIII, IX, and X are apparently synthesized by the liver and released into the circulation. The prothrombin precursor, known as preprothrombin, is antigenically similar to prothrombin but differs in electrophoretic mobility from prothrombin when subjected to electrophoresis in the presence of calcium. Preprothrombin does not bind calcium, unlike prothrombin, and for this reason is converted into thrombin only at very low rates in the presence of activated factor $\mathrm{X}$, factor $\mathrm{V}$, and phospholipid. However, other enzymes, such as staphylocoagulase, are able to convert preprothrombin to thrombin as easily as prothrombin. The precursor molecules of the vitamin K-dependent factors act as competitive inhibitors to their active analogues, and thus the action of the oral anticoagulants is both to produce a deficiency of vitamin K-dependent clotting factors and to induce inhibitors to them. These inhibitors are known as PIVKA (protein induced by vitamin $\mathrm{K}$ absence or antagonists) and the inhibitor to factor $X$ has been studied most intensively (Hemker, Veltkamp, and Loeliger, 1968).

The chief complication of all anticoagulants is, of course, haemorrhage. The cause of the haemorrhage is usually due either to excessive dosage of the anticoagulants or to an unidentified source of haemorrhage, such as a peptic ulcer.

One major problem of the oral anticoagulants is that they interact with numerous other drugs with the result that their effect may either be diminished or increased (Eipe, 1972). In the first instance, loss of control may lead to further thrombosis and in the second instance to haemorrhage. The coumadin compounds are transported bound to albumin and drugs which displace the coumadins from their binding sites increase their anticoagulant action; such drugs are phenylbutazone, indomethacin, and clofibrate. Other drugs which can enhance the effect of anticoagulants include those (1) causing impaired vitamin $\mathrm{K}$ absorption, eg, neomycin; (2) causing delayed degradation of coumadins, eg, diphenylhydantoin, tolbutamide; (3) causing increased affinity of coumadins to the hepatic receptor site, eg, clofibrate, D-thyroxine.

Many drugs causing enzyme induction increase 
the rate at which the coumadins are degraded leading to a diminution in the anticoagulant effect. Drugs in this category include the barbiturates and meprobamate.

A few families have a remarkable hereditary resistance to the effect of the oral anticoagulants (O'Reilly, 1970). Individuals may take up to twenty times the normal dose yet show merely the normal or even less than normal anticoagulant effect. The absorption rate, albumin binding, and turnover rate in these families are normal. The defect appears to lie in an altered affinity of the hepatic receptor site for the anticoagulant and for vitamin $\mathrm{K}$, caused by a single dominant effect on an autosomal chromosome.

\section{ANCROD}

Ancrod is the purified coagulant fraction of the venom of Agkistrodon rhodostoma, the Malayan pit viper. This enzyme removes fibrinopeptide A from fibrinogen leading to the formation of an unstable form of fibrin which is rapidly removed from the circulation by fibrinolysis (Ewart, Hatton, Basford, and Dodgson, 1970). We have evidence to suggest that the fibrin is cleared from the circulation as soon as it is in the form of high molecular weight soluble fibrin complexes, and that the formation of insoluble 'micro-thrombi' does not occur under normal circumstances (McKillop, Edgar, Forbes, and Prentice, 1975). One interesting consequence of defibrination by ancrod is that the whole blood and plasma viscosity are diminished. This may be an important effect in promoting blood flow in small vessels and there are encouraging reports from the Continent that ancrod may be helpful in the treatment of peripheral arterial diseases.

\section{INDICATIONS FOR ANTICOAGULANTS}

The indications for anticoagulants are shown in table II. It should be noted that the main indications occur in the realm of venous disease, such as deep vein thrombosis and pulmonary embolism. The indications for arterial disease, such as transient cerebrovascular ischaemia or myocardial infarction, are much less certain.

\begin{tabular}{|c|c|}
\hline Indication & Condition \\
\hline Definite & $\begin{array}{l}\text { Deep-vein thrombosis } \\
\text { Pulmonary embolism } \\
\text { Mitral valve disease } \\
\text { Prosthetic cardiac valves } \\
\text { Extracorporeal circulations } \\
\text { Prophylaxis-deep-vein thrombosis }\end{array}$ \\
\hline Probable & Transient ischaemic attacks \\
\hline Possible & $\begin{array}{l}\text { Myocardial infarction } \\
\text { Ingravescent angina }\end{array}$ \\
\hline
\end{tabular}

Table II Indications for anticoagulants
There are, at present, no definite indications for ancrod. It appears to be as effective as heparin for the treatment of deep vein thrombosis, and control of ancrod may be easier than of heparin. Possibly the most dramatic effects with ancrod have been obtained in the treatment of priapism (Bell and Pitney, 1969).

\section{Thrombolytic Therapy}

In many ways the idea of a drug that dissolves an existing thrombus instead of merely preventing further fibrin deposition is attractive. Unfortunately, there appears to be great variability in the susceptibility of different thrombi to lysis, and it is not easy to predict which thrombi will respond to lytic therapy. The main fibrinolytic enzyme is streptokinase (molecular weight 43000 ) obtained from the streptococcus. Streptokinase acts in a complex manner which is not fully understood. It appears to react with a plasminogen pro-activator to activate plasminogen to plasmin. Streptokinase then complexes with plasmin to activate further plasminogen by first-order kinetics. Plasmin is a protease of wide specificity, digesting not only fibrin and fibrinogen but also factors V and VIII. When it is remembered that the digestion products of fibrinogen are anticoagulant it is not surprising that streptokinase can produce a severe bleeding tendency.

The major problem arising from streptokinase is that it can give rise to pyrogenic and allergic reactions. Additionally, due to the different levels of streptococcal antibodies present in the population, ideally a streptokinase sensitivity test should be carried out before treatment. Treatment with streptokinase cannot be repeated within six months of a previous course.

Urokinase, prepared from human urine, is not generally available and the cost for a course of whole body lysis is prohibitive. Unlike streptokinase, urokinase is a direct activator of plasminogen by splitting of lysine and arginine bonds and appears to cause less systemic digestion of fibrinogen in comparison with streptokinase. It is not associated with pyrogenic reactions and predicting dosage is easier than with streptokinase as it is unaffected by the streptococcal inhibitors. Some of the earlier preparations of urokinase were contaminated with a coagulant moiety, but this problem has now been overcome.

\section{Pharmacological Enhancement of Fibrinolysis}

A number of agents have the ability to augment the level of circulating plasminogen activator which can be demonstrated in low amounts within the normal 
circulation. One source of this activator is vascular endothelium, in particular venous endothelium. As patients with arterial disease, such as survivors of myocardial infarction, tend to have reduced plasminogen activator levels, these compounds are clearly of great interest. The main agents under trial are phenformin, ethyloestrenol, and stanozolol, an anabolic steroid. The mode of their action is not known.

\section{Indications for Fibrinolytic Therapy}

As seen in table III, there are to date no definite indications for fibrinolytic therapy, although many clinicians would now use streptokinase as the treatment of first choice in massive pulmonary

\begin{tabular}{ll}
\hline Indication & Condition \\
\hline Probable & $\begin{array}{l}\text { Massive pulmonary embolism } \\
\text { Ilio-femoral deep vein thrombosis } \\
\text { Hyphaema of eye } \\
\text { Pyossible }\end{array}$ \\
& $\begin{array}{l}\text { Myocardial infarction } \\
\text { Peripheral arterial disease }\end{array}$ \\
\hline
\end{tabular}

Table III Indications for fibrinolytic agents

embolism or ilio-femoral deep vein thrombosis. The subject has been reviewed recently (Prentice and McNicol, 1973). Although streptokinase and urokinase can, in massive pulmonary embolism, lower the pulmonary artery pressure more rapidly than heparin, no beneficial effect on the mortality from pulmonary embolism has yet been found. Streptokinase is widely used for the treatment of peripheral arterial disease on the Continent, but this approach has not been tested widely in Britain.

\section{References}

Bell, W. R., and Ptiney, W. R. (1969). Management of priapism by therapeutic defibrination. New Engl.J. Med., 280, 649-650.

Eipe, J. (1972). Drugs affecting therapy with anticoagulants. Med. Clin. N. Amer., 56, 255-262.

Ewart, M. R., Hatton, M. W. C., Basford, J. M., and Dodgson, K. S. (1970). The proteolytic action of Arvin on human fibrinogen. Biochem, J., 118, 603-609.

Hemker, W. C., Veltkamp, J. J., and Loeliger, E. A. (1968). Kinetic aspects of the interaction of blood clotting enzymes. III. Demonstration of an inhibitor of prothrombin conversion in Vitamin K deficiency. Thrombos. Diathes, haemorrh. (Stuttg.), 19, 346-363.

Lindsay, R. M., Prentice, C. R. M., Ferguson, D., Burton, J. A., and McNicol, G. P. (1972). Reduction of thrombus formation on dialyser membranes by aspirin and R.A.233. Lancet, 2, 1287-1290.

McKillop, C., Edgar, W., Forbes, C. D., and Prentice, C. R. M. (1975) Soluble fibrin complex production and proteolysis during Ancrod therapy. Communication to Scottish Society for Experimental Medicine, Edinburgh.

O'Reilly, R. A. (1970). The second reported kindred with hereditary resistance to oral anticoagulant drugs. New Engl. J. Med., 282, 1448-1451.

Prentice, C. R. M., and McNicol, G. P. (1973). Fibrinolytic therapy. In Recent Advances in Thrombosis, edited by L. Poller. pp. 151179 Churchill Livingstone, Edinburgh and London.

Thomson, C., Forbes, C. D., and Prentice, C. R. M. (1973). The potentiation of platelet aggregation and adhesion by heparin in vitro and in vivo. Clin. Sci., 45, 485-494.

Vermylen, J., de Gaetano, G., and Verstraete, M. (1973). Platelets and thrombosis. In Recent Advances in Thrombosis, edited by $\mathrm{L}$. Poller, pp. 113-150. Churchill Livingstone, Edinburgh and London. 